Www.jmscr.igmpublication.org

Index Copernicus Value: 79.54

ISSN (e)-2347-176x ISSN (p) 2455-0450

crossrefDOI: https://dx.doi.org/10.18535/jmscr/v7i2.21

\title{
Quality of Life and Functional Disability in Patients with Obsessive Compulsive Disorder
}

\author{
Authors \\ Niska Sinha ${ }^{1}$, Satish Kumar Sinha ${ }^{2 *}$ \\ ${ }^{1}$ Assistant Professor of Psychiatry, Indira Gandhi Institute of Medical Sciences, Patna \\ ${ }^{2}$ Assistant Professor and Head, Department of Psychiatry, Anugrah Narayan Medical College and Hospital, \\ Gaya, Bihar \\ *Corresponding Author \\ Satish Kumar Sinha
}

Department of Psychiatry, Anugrah Narayan Medical College and Hospital, Gaya, Bihar, India

Email: Satishshishir@gmail.com

\begin{abstract}
Background: Obsessive compulsive disorder $(O C D)$ is an anxiety disorder which is chronic and incapacitating illness that causes profound impairment in psychosocial functioning and quality of life.

Materials and Methods: The present study was conducted with an aim to study the quality of life and disability between obsessive compulsive disorder and control group. A cross-sectional study was conducted with a sample size comprising of 40 patients of OCD and matched healthy controls after obtaining Ethical Committee approval. Patients were assessed using a semi-structured Sociodemographic proforma, Yale-Brown Obsessive-Compulsive Scale (Y-BOCS), Sheehan Disability Scale (SDS), WHO Quality of life-BREF (WHO-QOL-BREF). Data was evaluated using the Statistical Package for the Social Sciences (SPSS Inc. version 17.0).

Results: Poor quality of life in physical, psychological, social and environment domains as well as overall quality of life was found in OCD patient group as compared to control group. The OCD patient group was significantly more disabled compared to control group in work, social, environment domains as well as overall disability. Severity of OCD correlated positively with disability whereas it correlated negatively with quality of life.
\end{abstract}

Keywords: Quality of life, functional disability, obsessive compulsive disorder.

\section{Introduction}

Obsessive compulsive disorder (OCD) is an anxiety disorder characterized by recurrent, persistent and intrusive thoughts, images or impulses that are difficult to control and cause considerable distress or anxiety (obsessions) and repetitive ritualistic behaviors or mental acts performed excessively to relieve distress or anxiety caused by obsessions (compulsions). ${ }^{1}$ Obsessive-compulsive disorder is the fourth most common psychiatric disorder. The Epidemiological Catchment Area study reported a point prevalence of $1.3 \%$ and a lifetime prevalence of $2.5 \%$ in the general population. ${ }^{2}$ OCD is a chronic and disabling illness that impacts occupational, social, and family 
functioning of patients and may affect the quality of life of a person.

The course of OCD is chronic, such chronicity leads to significant functional impairment and hence therefore reduced quality of life (QOL). According to the World Health Organisation, OCD is among the 10 most disabling medical conditions worldwide by lost income and decreased quality of life. ${ }^{3}$ Functional impairment, refers to quantifiable difficulty engaging in activities (e.g., work, social, leisure activities) due to psychological symptoms. Individuals with OCD demonstrate substantial functional impairment, as they are unable to work effectively and efficiently, perform household tasks, or fulfill social duties as a result of their obsessions and compulsions. $^{4}$

Quality of life refers to subjective well-being, including enjoyment and satisfaction with various life activities. Since obsessions are experienced as intrusive and uncontrollable, they generate distress, and compulsions which are recognized as irrational but indispensable by the patient to manage anxiety and distress have an impact on QOL. ${ }^{5}$ Moreover, these are may be affected by the severity of illness. ${ }^{6}$ However, the degree of OCDspecific psychosocial and functional impairment among affected adults have not yet being systematically documented. ${ }^{7,8}$ More so, co-relation among the functional impairment and quality of life with severity of OCD needs to be assessed.

There is a dearth of literature on the correlation between the QOL and functional impairment. Thus, the present study was planned with a focus on the functional impairment and QOL of a patient with OCD and to establish the relationship among them with the severity of OCD. The findings from the current study will be helpful in the management of this group of patients in preventing them from further deterioration from illness.

\section{Materials and Methods}

The aim of the study was to study the quality of life and disability between obsessive compulsive disorder and control group. Also, to study the correlation of severity of OCD with quality of life and disability in obsessive compulsive disorder group. It was a cross-sectional hospital based study carried out in a government medical college of Gaya, Bihar during the period of year 20152016. The sample size consisted of 40 cases of Obsessive Compulsive Disorder and 40 healthy matched controls, enrolled for the study after obtaining ethics committee approval. It included 40 patients satisfying the Diagnostic Criteria for Research (DCR) for obsessive compulsive disorder of International Classification of Diseases- tenth edition (ICD-10, World health organization, 1993) $)^{9}$ and 40 matched healthy controls age 18-45 of both sexes willing to participate in the study and who gave their consent. Those with major neurological and physical disorder or any other major co-morbid psychiatric diagnosis or substance dependence excluding nicotine \& caffeine were excluded from the study. Purposive sampling technique was used and a semi-structured Socio-demographic Performa specially designed for the study along with the scales were.

\section{Tools Used}

Sociodemographic and Clinical Data Sheet: It included socio-demographic variables like name, age sex, religion, marital status, years of education, occupation, annual family income, family type and residence and clinical variables including diagnosis (ICD-10), clinical details as onset, course, duration of illness, history of present illness, drug status, treatment history, past history of psychiatric illness, family history of psychiatric illness, premorbid personality and mental status examination.

\section{Yale-Brown Obsessive-Compulsive Scale (Y- BOCS)}

This scale, designed by Wayne Goodman and his colleagues (Goodman et al, 1989), measures obsessions separately from compulsions and specifically measures the severity of symptoms of 
OCD. ${ }^{10}$ The scale is a clinician-rated, 10-item scale, with additional item 11 for assessing insight, each item rated on 5 point scale from 0 (not present), $1,2,3$ to 4 (severe).

\section{Sheehan Disability Scale (SDS)}

It was given by David Sheehan in the year 1983 (Sheehan, 1996). The SDS is a 3-item self-report questionnaire that assesses the level of impairment experienced due to illness in social, occupational, and family life. The impairment scores for each domain (possible scores range from 0 to 10) and the total score is calculated summing scores on each of three domains (possible scores range from 0 to 30). Higher scores indicate higher impairment. $^{11}$

\section{Whoqol-Bref}

Contains the 26 items divided in 4 domains that are physical health, psychological, social relationships and environmental. The scale is clinically rated 5-point rating scale ranging from 1 (not present) to 5 (severe). The test-retest reliability coefficients ranged from 0.41 to 0.79 at item/facet level and 0.76 to 0.80 at domain level (all $\mathrm{p}<0.01)^{12}$

\section{Statistical analysis}

In this study, the data was evaluated using the Statistical Package for the Social Sciences (SPSS Inc. version 17.0). The Statistical techniques used for analyzing data were frequencies, percentages and correlations. The statistical significance value was set at $\mathrm{p}<0.05$.

\section{Results}

In the present study, the mean age of OCD group was $28.5 \pm 7.7$ years. Majority of OCD patients were male, married, self-employed, Hindu coming from rural background and belonging to nuclear family. The analysis of socio-demographic profile revealed that both groups OCD and healthy controls were similar in respect to age, education, income, and gender, marital status, employment, religion, residence and type of family. The mean YBOCS obsessions score was 15.5 \pm 1.2 , compulsions $13.9 \pm 1.6$ and total score $29.4 \pm 2.5$ which indicates severe Obsessive Compulsive disorder. Diagnosis in the sample was OCD, predominantly obsessive thoughts in $3, \mathrm{OCD}$, predominantly compulsive acts in 2 and OCD, mixed obsession thoughts and acts in the majority i.e in 35 of the subjects.

Table 1: Comparison of Quality of Life in Obsessive compulsive disorder patient (OCD) group and Control group

\begin{tabular}{|l|c|c|c|c|}
\hline \multirow{2}{*}{ Variable } & OCD GROUP(N=40) & CONTROL GROUP $(\mathbf{N}=\mathbf{4 0})$ & $\mathbf{t}$ & \\
\cline { 2 - 6 } & $(\mathbf{d f}=\mathbf{7 8})$ & $\mathbf{p}$ \\
\hline Physical QOL & $24.13 \pm 2.19$ & $($ Mean \pm SD) & -4.20 & $<.001 * * * *$ \\
\hline Psychological QOL & $12.75 \pm 1.98$ & $25.78 \pm 1.19$ & -30.99 & $<.001 * * *$ \\
\hline Social QOL & $11.05 \pm 1.36$ & $24.80 \pm 1.45$ & -5.93 & $<.001 * * * *$ \\
\hline Environment QOL & $19.98 \pm 2.90$ & $12.48 \pm 0.68$ & -23.25 & $<.001 * * *$ \\
\hline QOL(total score) & $67.53 \pm 5.12$ & $32.70 \pm 1.88$ & -30.14 & $<.001 * * *$ \\
\hline
\end{tabular}

Table 1 shows comparison of Quality of life in OCD patient group $(\mathrm{N}=40)$ and Control group $(\mathrm{N}=40)$ using WHO-QOL BREF scores on various domains i.e. physical, psychological, social and environment as well as on total score for quality of life; applying independent $t$ test. Results showed statistically significant differences in quality of life in all domains as well as on overall quality of life in both the groups. It showed poor quality of life in physical, psychological, social and environment domains as well as on total score for quality of life in OCD patient group as compared to control group. 
Table 2: Comparison of Disability in Obsessive compulsive disorder patient (OCD) group and Control group:

\begin{tabular}{|c|c|c|c|c|}
\hline \multirow{2}{*}{ Variables } & $\begin{array}{c}\text { OCD GROUP } \\
(\mathrm{N}=40)\end{array}$ & $\begin{array}{c}\text { CONTROL } \\
\text { GROUP }(\mathrm{N}=40)\end{array}$ & \multirow{2}{*}{$\begin{array}{c}t \\
(d f=78)\end{array}$} & \multirow[t]{2}{*}{$\mathbf{p}$} \\
\hline & $($ Mean \pm SD) & $($ Mean \pm SD) & & \\
\hline Work & $6.38 \pm 0.87$ & $1.28 \pm 0.85$ & 26.60 & $<.001 * * *$ \\
\hline Social & $5.78 \pm 0.86$ & $2.28 \pm 0.99$ & 16.90 & $<.001 * * *$ \\
\hline Family life & $5.58 \pm 0.87$ & $0.73 \pm 0.88$ & 24.78 & $<.001 * * *$ \\
\hline Disability(total) & $17.73 \pm 1.75$ & $4.23 \pm 2.21$ & 33.93 & $<.001 * * *$ \\
\hline
\end{tabular}

Table 2 shows comparison of Disability in OCD patient group $(\mathrm{N}=40)$ and Control group $(\mathrm{N}=40)$ using independent $t$ test on Sheehan Disability Scale (SDS) scores on various domains. Results showed statistically significant differences in disability in all domains i.e. Work, Social, Family Life as well as total disability scores in both the groups. The OCD patient group was significantly more disabled compared to control group.

Table 3: Correlation between severity of OCD and Various Clinical Variables in Obsessive Compulsive Disorder patient (OCD) group: $(\mathrm{N}=40)$

\begin{tabular}{|c|c|c|c|}
\hline & & Quality Of Life & Disability \\
\hline \multirow[b]{2}{*}{ YBOCS Obsessions } & $\mathbf{r}$ & -.541 & .415 \\
\hline & $\mathbf{p}$ & $<.001 * *$ & $.008 * *$ \\
\hline \multirow{2}{*}{$\begin{array}{l}\text { YBOCS } \\
\text { Compulsions }\end{array}$} & $\mathbf{r}$ & -.423 & .476 \\
\hline & $\mathbf{p}$ & $.007 * *$ & $.002 * *$ \\
\hline \multirow[b]{2}{*}{ YBOCS Total } & $\mathbf{r}$ & -.516 & .487 \\
\hline & $\mathbf{p}$ & $.001 * *$ & $.001 * *$ \\
\hline
\end{tabular}

Table 3 shows Pearson's correlation analysis of severity of OCD on YBOCS scores and quality of life, disability in obsessive compulsive disorder patient (OCD) group. Total YBOCS score correlated positively with disability whereas it correlated negatively with quality of life. The same pattern of correlation was also observed with increased severity of obsessions and compulsions.

\section{Discussion}

Present sample characteristics are in accordance with the studies carried out on the same population in this country, as well as in western countries. Poor quality of life in physical, psychological, social and environment domains as well as overall quality of life was found in OCD patient group as compared to control group. The OCD patient group was significantly more disabled compared to control group in work, social, environment domains as well as overall disability. Severity of OCD correlated positively with disability whereas it correlated negatively with quality of life. The same pattern of correlation was also observed with increased severity of obsessions and compulsions.

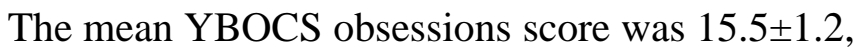
compulsions $13.9 \pm 1.6$ and total score $29.4 \pm 2.5$ which indicates severe Obsessive Compulsive disorder in our study sample and is an expected finding since the government institute being a health care centre catering to severe psychiatric illnesses from its catchment areas. OCD patients had poorer quality of life in physical, psychological, social and environment domains as compared to the control group. Also the overall quality of life in OCD patients was poorer in them. This is in concordance with studies from larger sample sizes like Rapaport et al, 2005 and Huppert et al in 2009. ${ }^{4,14}$

Our study, revealed significantly high degree of functional impairment in OCD than healthy control with the patient population showing 
marked impairments in all areas functioning. This has also been found to be consistent with the observations made by earlier researchers. Previous researchers also found the same finding regarding this area, and they mentioned that intractable OCD might cause a very severe negative impact on the sufferers' personal and interpersonal functions. The OCD patients were more disabled as compared to normal controls. There was a significant difference seen in all domains of disability i.e. work, social, family life. ${ }^{4,8,14}$ These findings resembled those found by others like Bobes et al. (2001); Huppert et al. (2009); Lopez and Murray (1998). ${ }^{15}$

Majority of the OCD patients had a diagnosis of OCD, mixed obsessional thoughts and acts $(87.5 \%) .{ }^{13}$ This is in accordance with the findings in available literature (Khanna and Reddy, 2004) Present sample characteristics are in accordance with the studies carried out on the same population in this country, as well as in western countries. Severity of OCD correlated positively with disability whereas it correlated negatively with quality of life. The same pattern of correlation was also observed with increased severity of obsessions and compulsions. Similar findings were reported by Eisen et al. (2006); Rapaport et al. (2005); Huppert et al. (2009) in correlation of severity of OCD with quality of life; Bobes et al. (2001), Huppert et al. (2009) in correlation of severity of OCD with disability. ${ }^{4,5,14}$

\section{Limitations}

The study was a cross sectional hospital based study. Participants were treatment seeking, and therefore, our findings may not apply to those individuals with OCD who do not seek treatment. The patients selected from only one medical college, and hence the results cannot be generalized. In future, studies with community sample or even taking different medical colleges from all parts of India are needed more so with a longitudinal study design.

\section{Conclusion}

The study reveals significant amount of disability and decreased quality of life as compared to healthy controls Additional research is needed to assess which aspects of QOL and psychosocial functioning can be helped by therapies, so that specific treatment approaches can be planned.

\section{Financial support and sponsorship: Nil \\ Conflict of Interest: None declared}

\section{References}

1. American Psychiatric Association. Diagnostic and statistical manual of mental disorders (Fifth ed.). Washington DC: American Psychiatric Association; 2013.

2. Regier DA, Farmer ME, Rae DS, Myers JK, Kramer M, Robins LN. One-month prevalence of mental disorders in the United States and sociodemographic characteristics: The Epidemiologic Catchment Area study. Acta Psychiatrica Scandinavica 1993; 88:35-47.

3. World Health Organization. The 'newly defined' burden of mental problems. Fact Sheet, No.217. Geneva, Switzerland: World Health Organization; 1999.

4. Rapaport MH, Clary C, Fayyad R, Endicott J. Quality of life impairment in depressive and anxiety disorders. American Journal of Psychiatry 2005; 162:1171-78.

5. Eisen JL, Mancebo MA, Pinto A, Coles ME, Pagano ME, Stout R. Impact of obsessive-compulsive disorder on quality of life. Comprehensive Psychiatry 2006; 47(4):270-5.

6. Reddy YC, Srinath S, Prakash HM, Girimaji SC, Sheshadri SP, Khanna S. An overview of Indian research in Obsessive compulsive disorder. Indian Journal of Psychiatry 2010; 52:200-9.

7. Storch EA, Abramowitz JS, Keeley M. Correlates and mediators of functional disability in obsessive-compulsive 
disorder. Depression and Anxiety 2009; 26(9):806-13.

8. Bobes J, González MP, Bascarán MT, Arango C, Sáiz PA, Bousoño M. Quality of life and disability in patients with obsessive-compulsive disorder. Eur Psychiatry. 2001;16:239-45.

9. World Health Organization. The Tenth Revision of the International Statistical Classification of Diseases and Related Health Problems (ICD-10): Diagnostic Criteria for Research. Geneva: World Health Organization; 1993.

10. Goodman WK, Price LH, Rasmussen SA. The Yale-Brown Obsessive Compulsive Scale: Development, use, and reliability. Archives of General Psychiatry 1989; 46:1006-11.

11. Sheehan DV, Harnett S, Raj BA. The measurement of disability. International Clinical Psychopharmacology 1996; 11(3):89-95.

12. Yao G, Chang CW, Yu FC, Wang JD. Development and verification of validity and reliability of the WHOQOL-BREF. Journal of Formosan Medical Association 2002; 101:342-51.

13. Khanna S, Reddy YJ. Obsessive Compulsive Disorder - an Indian perspective. Mumbai: Abbott India Lenbrook Division Publishing; 2004.

14. Huppert JD, Simpson HB, Nissenson KJ, Liebowitz MR, Foa EB. Quality of life and functional impairment in obsessivecompulsive disorder: a comparison of patients with and without comorbidity, patients in remission, and healthy controls. Depression and Anxiety 2009; 26(1):3945.

15. Lopez AD, Murray CC. The global burden of disease:1990-2020. Nature Medicine 1998;4(11):1241-43. 